Supporting Information for :

\title{
Oxygenation of a Ruthenium(II) Thiolate to a Ruthenium(II) Sulfinate Proceeds via Ruthenium(III)
}

Craig A. Grapperhaus, ${ }^{*}$ Selma Poturovic, and Mark S. Mashuta

Department of Chemistry, University of Louisville, Louisville, Kentucky 40292

Table of Contents

page

Experimental Notes

S2-S3

ESI-MS of [PPN][Ru(DPPBT-O $\left.)_{2}(\mathrm{DPPBT})\right]$ in $\mathrm{CH}_{2} \mathrm{Cl}_{2} / \mathrm{THF}$

S4

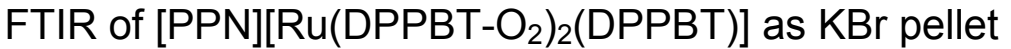

S4

Cyclic voltammogram of [PPN][Ru(DPPBT-O $\left.)_{2}\right)_{2}($ DPPBT $\left.)\right]$

S5

References for Supporting Information

S5 


\section{Experimental Notes}

\section{Instrumentation}

UV-vis spectra was recorded with an Agilent 8453 diode array spectrometer with $1 \mathrm{~cm}$ pathlength quartz cells. Infrared spectra were recorded as $\mathrm{KBr}$ pellets using Thermo Nicolet Avatar 360 Fourier transform single beam spectrometer. Elemental analysis were obtained from Midwest Microlab, LLC in Indianapolis, Indiana. ESI mass spectroscopy was obtained at University of Louisville Mass Spectroscopy Core Laboratory. The X-ray data was collected by SMART CCD Bruker diffractometer with array detector.

\section{Crystallographic Studies}

A thin yellow plate $0.31 \times 0.21 \times 0.02 \mathrm{~mm}^{3}$ crystal of [PPN][Ru(DPPB$\left.\mathrm{O}_{2}\right)_{2}$ (DPPBT)] was mounted on a $0.05 \mathrm{~mm}$ CryoLoop with Paratone oil for collection of x-ray data on a Bruker SMART APEX CCD diffractometer. The SMART $^{1}$ software package ( $v$ 5.628) was used to acquire a total of 1,868 thirtysecond frame $\omega$-scan exposures of data at $100 \mathrm{~K}$ to a $20 \mathrm{max}=54.74^{\circ}$ using monochromated Mo Ka radiation $(0.71073 \AA)$ from a sealed tube and a monocapillary. Frame data were processed using SAINT ${ }^{2}$ ( $v$ 6.36) to determine final unit cell parameters $a=13.528(2) \AA, b=15.278(3) \AA, c=19.181(3) \AA, \alpha=$ $98.811(3)^{\circ}, \beta=96.488(3)^{\circ}, \gamma=92.197(3)^{\circ}, V=3886.2(11) \AA^{3}, Z=2$ and $\rho_{\text {calcd }}=$ $1.353 \mathrm{Mgm}^{-3}$ to produce raw hkl data that were then corrected for absorption (transmission min./max. $=0.86 / 0.97 ; \mu=0.438 \mathrm{~mm}-1$ ) using $\operatorname{SADABS}^{3}$ (v 2.02). The structure was solved by Patterson methods in the space group P-1 using SHELXS- $90^{4}$ and refined by least squares methods on $F^{2}$ using SHELXL-97 incorporated into the SHELXTL ${ }^{6}$ ( $\mathrm{V}$ 6.12) suite of programs. A hexane molecule is disordered and a suitable model could not be obtained. Its contribution was subtracted from the data using the program SQUEEZE. ${ }^{7}$ All non-hydrogen atoms were refined anisotropically. Phenyl H's were calculated and assigned $U(H)=$ $1.2 \times$ Ueq. For all 16165 unique reflections $(R($ int $)=0.0598)$ the final anisotropic full matrix least-squares refinement on $F^{2}$ for 937 variables converged at $\mathrm{R} 1=$ 0.139 and $w R 2=0.146$ with a GOF of 1.07

X-ray structural analysis for $\left[\mathrm{Ru}\left(\mathrm{DPPBT}-\mathrm{O}_{2}\right)_{2}(\mathrm{DPPBT})\right]$ was preformed at $293 \mathrm{~K}$ on a $0.30 \times 0.26 \times 0.04 \mathrm{~mm}^{3}$ green prism crystal using an identical data acquisition strategy described above for $[P P N]\left[R u\left(D P P B-O_{2}\right)_{2}(D P P B T)\right]$ to a $2 \theta \max =55.36^{\circ}$. [Ru(DPPBT-O $\left.)_{2}(\mathrm{DPPBT})\right]$ crystallizes in the monoclinic space group $\mathrm{C} 2 / \mathrm{c}$ with unit cell parameters $\mathrm{a}=18.374(3) \AA, b=12.436(2) \AA, \mathrm{c}=$ 40.497(6) $\AA, \beta=99.995(3)^{\circ}, V=9113(2) \AA^{3}, Z=8$ and $\rho_{\text {calcd }}=1.500 \mathrm{Mgm}^{-3}$. All raw independent reflections were corrected for absorption (transmission $\min . / \max .=0.81 / 0.95 ; \mu=0.633 \mathrm{~mm}-1)$ using $\operatorname{SADABS}^{3}$ (v 2.02). The structure was solved by Patterson methods and refined on $F^{2}$ using SHELXTL. All nonhydrogen atoms were refined anisotropically. Phenyl H's were calculated and assigned $\mathrm{U}(\mathrm{H})=1.2 \mathrm{x}$ Ueq. For all 10450 unique reflections $(R(\mathrm{int})=0.042)$ the final anisotropic full matrix least-squares refinement on $F^{2}$ for 586 variables converged at R1 $=0.096$ and $w R 2=0.128$ with a GOF of 1.07. 


\section{Synthetic Notes}

Solvents were obtained from VWR and Aldrich Chemical Company, and were dried prior to use according to the standard procedures. The precursor complex $[\mathrm{PPN}]\left[\mathrm{Ru}(\mathrm{DPPBT})_{3}\right]$ was synthesized according to the previously published procedure. $^{8}$

[PPN][Ru(DPPBT-O $\left.)_{2}\right)_{2}($ DPPBT)]. A $150 \mathrm{~mL}$ acetonitrile solution of [PPN][Ru(DPPBT $\left.)_{3}\right](0.150 \mathrm{~g}, 98.7 \mu \mathrm{mol})$ was stirred under oxygen atmosphere for 48 hours. The color of the solution transformed from orange to red-brown within one hour and to a final yellow solution within 39 hours. The solvent was removed in vacuo and the solid slurried in THF. The yellow solution was separated via gravity filtration and the solvent was removed in vacuo yielding a yellow solid $(72 \%)$. Recrystallization from dichloromethane/hexanes produced yellow plate crystals. Elemental analysis of $\mathrm{C}_{90} \mathrm{H}_{72} \mathrm{NO}_{4} \mathrm{P}_{5} \mathrm{RuS}_{3}$ experimental (calculated):C 68.06 (68.26); H 4.42 (4.58). ESI-MS (dichloromethane/THF, m/z negative ion): 1045. FTIR ( $\mathrm{KBr}$ pellet, $\left.\mathrm{cm}^{-1}\right)$ 3051(m), 1440(s), 1115(s), 1017(s), 694(s). UV-visible spectroscopy (acetonitrile, $\lambda(\varepsilon)): 402(2370)$.

[Ru(DPPBT- $\left.\left.)_{2}\right)_{2}(\mathrm{DPPBT})\right]$. Bulk electrolysis of [PPN][Ru(DPPBT-O $\left.)_{2}(\mathrm{DPPBT})\right]$ was performed in acetonitrile $(1 \mathrm{mM})$ at an applied potential of $+550 \mathrm{mV}$ to afford a green solution. Removal of the solvent followed by the extraction into toluene yield the product in pure form. [Ru(DPPBT- $\left.\left.{ }_{2}\right)_{2}(\mathrm{DPPBT})\right]$ can also be obtained from reaction of $[\mathrm{PPN}]\left[\mathrm{Ru}(\mathrm{DPPBT})_{3}\right]$ with trace amount of oxygen in chlorobenzene. Green crystals of $\left[\mathrm{Ru}\left(\mathrm{DPPBT}-\mathrm{O}_{2}\right)_{2}(\mathrm{DPPBT})\right]$ were isolated from chlorobenzene/ diethyl ether at $0^{\circ} \mathrm{C}$. EPR (MeCN $\left.1 \mathrm{mM}\right)$ shows a rhombic signal with $\mathrm{g}=2.07,2.04,2.03 . \mathrm{E}_{1 / 2}=+255 \mathrm{mV}$ (in MeCN). FTIR $\left(\mathrm{KBr}\right.$ pellet, $\left.\mathrm{cm}^{-1}\right)$ : 694(m), 1025(s), 1119(s), 1262(s), 1434(m), 3056(s). UV-visible spectroscopy (acetonitrile, $\lambda(\varepsilon)):$ 369(3599), 651(1307). 


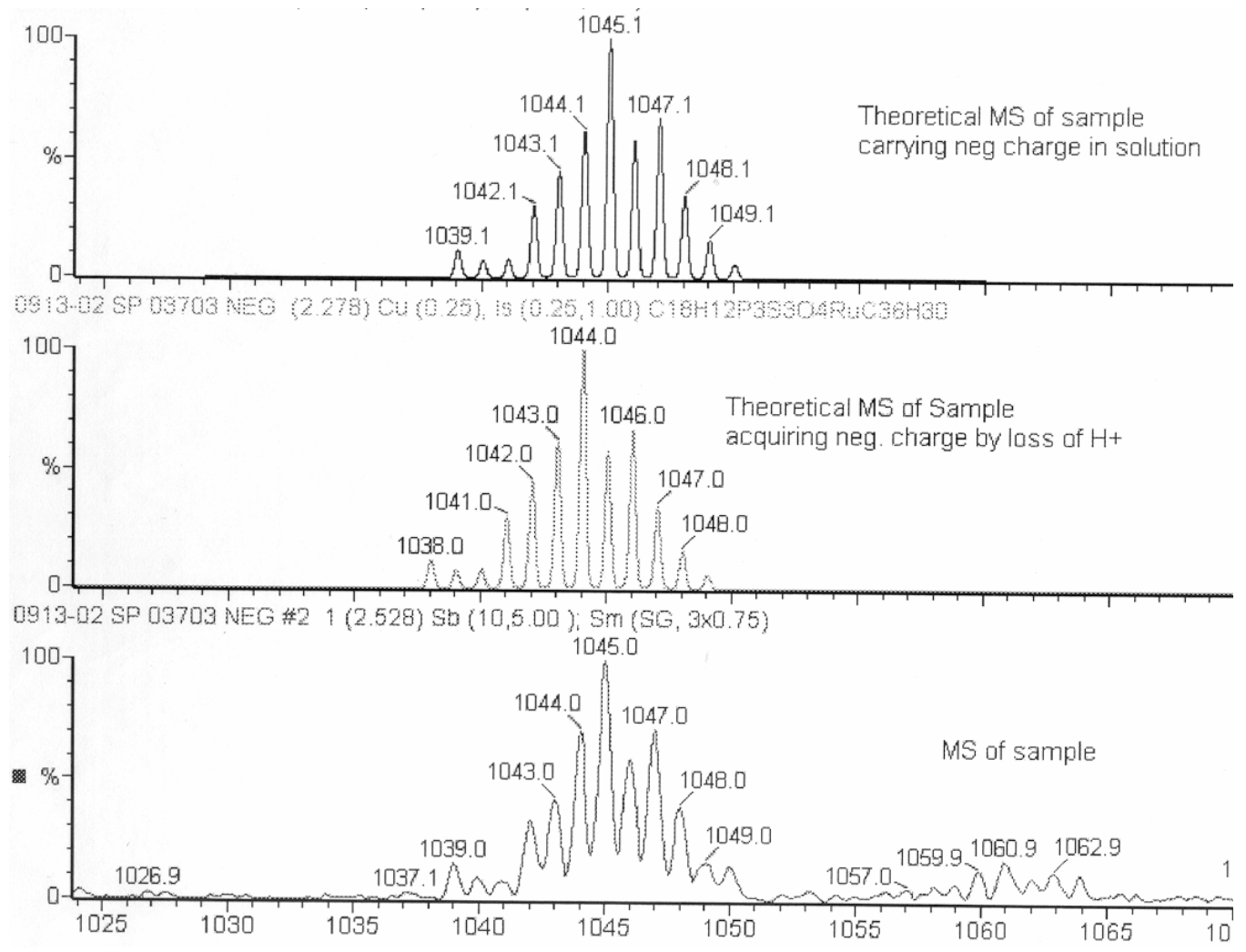

Figure S1. ESI-MS of [PPN][Ru(DPPBT-O $\left.)_{2}(\mathrm{DPPBT})\right]$ in $\mathrm{CH}_{2} \mathrm{Cl}_{2} / \mathrm{THF}$.

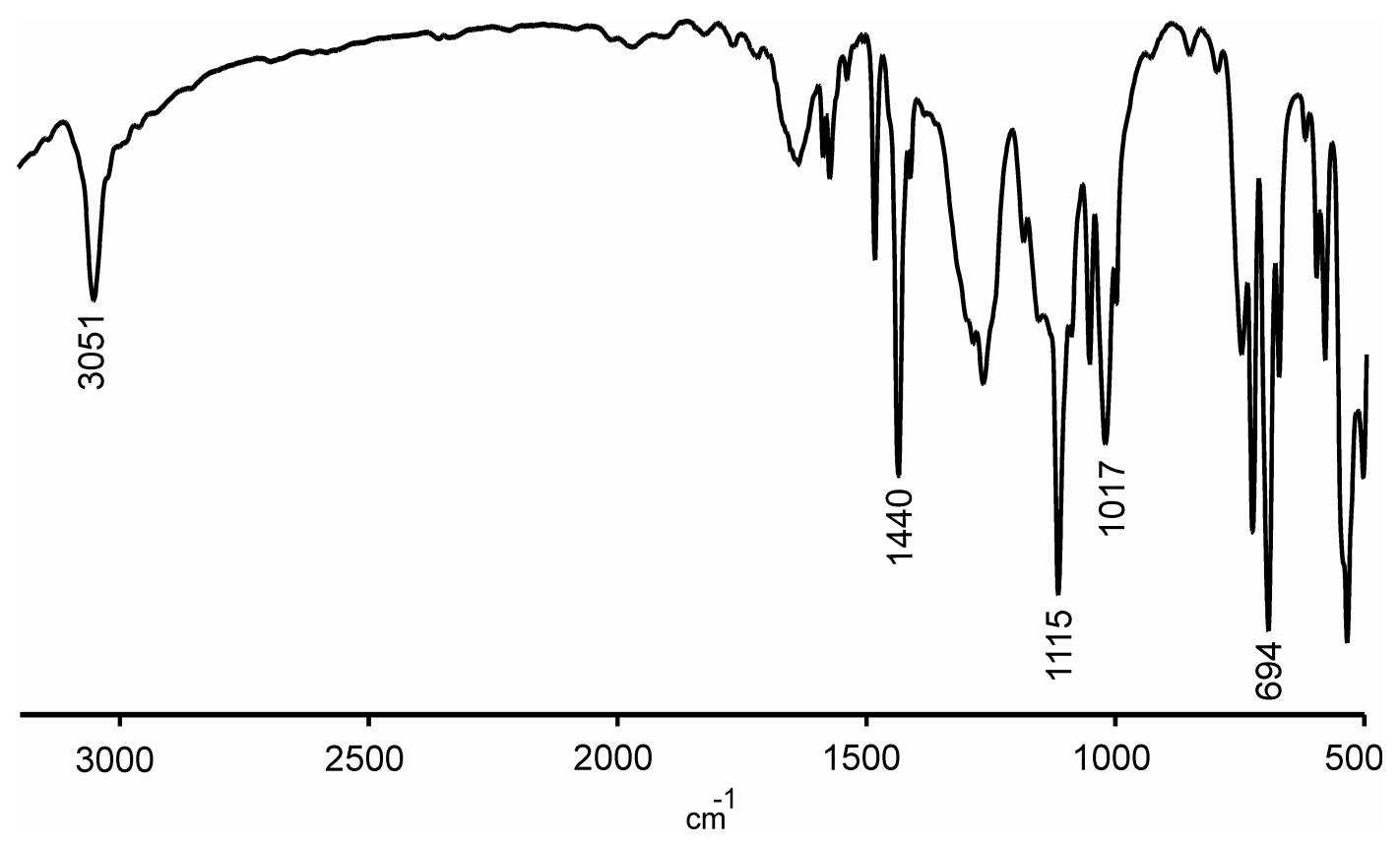

Figure S2. FTIR of [PPN][Ru(DPPBT-O $\left.)_{2}(\mathrm{DPPBT})\right]$ as $\mathrm{KBr}$ pellet. 

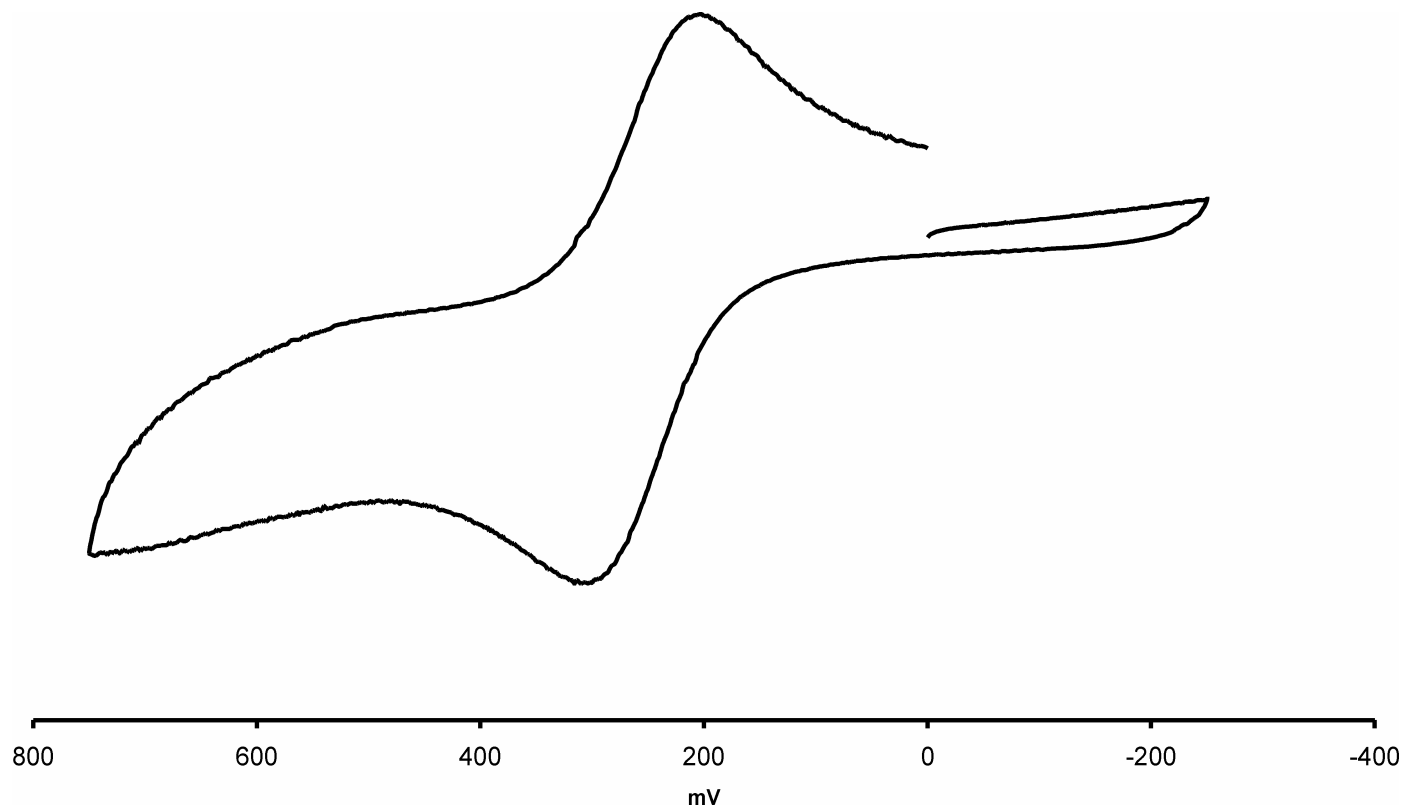

Figure S3. Cyclic voltammogram of [PPN][Ru(DPPBT- $\left.{ }_{2}\right)_{2}($ DPPBT $\left.)\right]$ in acetonitrile $(1 \mathrm{mM})$ at $200 \mathrm{mV} / \mathrm{s}$. Potentials obtained at glassy carbon electrode and referenced versus $\mathrm{Ag} / \mathrm{Ag}^{+}$.

\section{References for Supporting Information}

1. SMART (v.5628), Bruker Advanced X-ray Solutions, Inc.: Madison, WI, 2002.

2. SAINT (v6.36), Bruker Advanced X-ray Solutions, Inc.: Madison, WI, 2002.

3. Sheldrick, G. M. SADABS (v2.02), Area Detector Absorption Correction, University Gottingen:: Gottingen, Germany, 2001.

4. Sheldrick, G. M., Acta Crystallogr. 1990, A46, 467-473.

5. Sheldrick, G. M. SHELXL-97. Program for the Refinement of Crystal Structures, University Gottingen:: Gottingen, Germany, 1997.

6. SHELXTL (v6.12), Program Library for Structure Solution and Molecular Graphics, Bruker Advanced X-ray Solutions, Inc.:: Madison, WI, 2001.

7. Spek, A. L. PLATON, A Multipurpose Crystallographic Tool, Utrecht University, Utrecht, The Netherlands, 2005.

8. Grapperhaus, C. A.; Poturovic, S.; Mashuta, M. S., Inorg. Chem. 2002, 41, 4309-4311. 